\title{
Membrane lipid composition and glucose uptake in two psychrotolerant bacteria from Antarctica
}

\author{
NORIYUKi FukUNAGA ${ }^{1}$ and NichOlas J. RuSSELL ${ }^{2 *}$ \\ ${ }^{1}$ Department of Botany, Hokkaido University, Sapporo 060, Hokkaido, Japan \\ ${ }^{2}$ Department of Biochemistry, University of Wales, Cardiff CFI 1ST, UK
}

(Received 5 April 1990; revised 5 May 1990; accepted 22 May 1990)

\begin{abstract}
The thermal responses of membrane lipid composition and function in two bacterial species isolated recently from Heywood Lake sediment in Antarctica have been investigated. Both isolates are Gram-negative psychrotolerant (psychrotrophic) species growing well at 0 and $25^{\circ} \mathrm{C}$, but having very different optimum growth temperatures, of $9.7^{\circ} \mathrm{C}$ for strain $\mathrm{CR} 3 / \mathrm{F} / \mathrm{w} / 1 / 15$ and $20.9^{\circ} \mathrm{C}$ for strain $\mathrm{CR3} / \mathrm{F} / \mathrm{w} / 2 / 10$. The acyl lipids in strain $1 / 15$ contain predominantly branched-chain fatty acids, mainly anteiso-15:0. The fatty acid composition and its response to temperature depends on the culture medium used. In nutrient-poor medium a wider range is found, including unsaturated fatty acids, which are absent when a nutrient-rich medium is used. A decrease in growth temperature produced a shortening of the average fatty acid chain length in rich medium, whereas in poor medium there was a decrease in straight-chain, saturated and unsaturated relative to branched-chain fatty acids. The acyl lipids of strain $2 / 10$ contain $16: 0$ and 16:1 as the major fatty acids, particularly in rich medium, when they comprise $>90 \%$ of the total. Increasing proportions of 16:1 were converted to cyclopropane-17:0 at higher temperatures during growth in poor medium. A decrease in growth temperature in rich or poor medium resulted in an increase in the unsaturation index. When the bacteria were grown in rich or poor medium at $5{ }^{\circ} \mathrm{C}$ the strain with more 'psychrophilic' characteristics $(1 / 15)$ took up glucose at a faster rate than did the strain with more 'psychrotrophic' characteristics $(2 / 10)$, whereas when they were grown at $20^{\circ} \mathrm{C}$ in either medium the rate of glucose uptake by strain $2 / 10$ was generally faster than that of strain $1 / 15$. Thus, when the bacteria were grown at a low temperature the glucose uptake system of the more 'psychrophilic' strain was better adapted to function at zero, compared with that of the more 'psychrotrophic' strain. The basis of this difference is not due to the lack of temperature-dependent fatty acid changes, as reported previously for some other cold-adapted bacteria.
\end{abstract}

\section{Introduction}

Bacteria which are capable of growing at or close to $0{ }^{\circ} \mathrm{C}$ can be divided into two groups based on their cardinal growth temperatures, and the most widely accepted definitions are those of Morita (1975). Psychrophiles are defined as having optimum growth temperatures below $15^{\circ} \mathrm{C}$ and upper growth temperature limits below $20^{\circ} \mathrm{C}$. In contrast, psychrotrophs (psychrotolerants) have upper growth temperature limits above $20^{\circ} \mathrm{C}$ (sometimes as high as $40^{\circ} \mathrm{C}$ ) irrespective of the optimum growth temperature. Thus, compared with psychrotrophs, psychrophiles grow over a narrower temperature range. Although not all cold-adapted bacteria fit neatly into this classification, it is a useful scheme because it relates to the environmental origins of the two groups: psychrophiles tend to be isolated more frequently from thermally-stable cold (i.e. $<5{ }^{\circ} \mathrm{C}$ ) habitats, whereas psychrotrophs are more characteristic of thermallyunstable cold habitats (Baross \& Morita, 1978). However, it should be noted that relatively few truly psychrophilic species have been isolated even from permanently-cold environments (e.g. see Upton \& Nedwell, 1989; Delille \& Perret, 1989).

The question arises, 'are these two groups distinguishable by their biochemical characteristics?' It is well known that one of the most common adaptations to changes in temperature is in the fatty acid composition of membrane lipids, which enables an organism to sustain its membrane function at low temperatures (Russell, 1984,1989 ). Since psychrophiles and psychrotrophs have different thermal growth ranges, it is possible that this is due to differences in the extent or way in which the two groups modify their fatty acid compositions. There is evidence to suggest that psychrophiles are more likely than psychrotrophs to alter their fatty acid composition 
in response to low temperature (Bhakoo \& Herbert, 1979, 1980 ) and that this might be related to the ability of psychrophiles to take up nutrients better at zero than at higher temperatures (Herbert \& Bhakoo, 1979). The ability to take up solutes efficiently at low temperatures is generally regarded as one of the key features of psychrophilic (and psychrotrophic) micro-organisms, enabling them to grow at $0{ }^{\circ} \mathrm{C}$ (reviewed in Herbert \& Bhakoo, 1979; Russell, 1990). Ellis-Evans \& WynnWilliams (1985) found that glucose utilization at $0{ }^{\circ} \mathrm{C}$ was higher in a psychrotrophic bacterium isolated from a permanently-cold environment compared with a psychrotroph isolated from a thermally-unstable cold habitat. However, the hypothesis that efficient solute uptake due to modulation of fatty acid composition is a distinguishing feature of psychrophiles and psychrotrophs has been investigated in very few cold-adapted bacteria and not at all in those which span the accepted definitions of psychrophiles and psychrotrophs (vide supra). Therefore, we have analysed the fatty acid compositions and ability to take up glucose in two psychrotrophic bacteria isolated recently from lake sediment in Antarctica. Although both isolates have similar psychrotrophic growth temperature ranges, they have very different optimum growth temperatures, one being 'psychrophilic' and the other 'psychrotrophic'. Consequently, they are particularly suitable organisms with which to test the relationship between cardinal growth temperatures and the ability to modify membrane lipid composition and function.

\section{Methods}

Bacterial strains. The two psychrotrophic bacteria were isolated by Dr A. C. Upton (University of Essex, UK) from sediment obtained from Heywood Lake on Signy Island in the maritime Antarctic. Samples of sediment were enriched in two identical chemostats operating under different thermal regimes. Both chemostats used a modified FC2 medium (vide infra) and a dilution rate of $0.02 \mathrm{~h}^{-1}$ (Upton, 1988). Using a fluctuating 1 to $16^{\circ} \mathrm{C}$ temperature cycle the strain $\mathrm{CR} 3 / \mathrm{F} / \mathrm{w} / 1 / 15$ was isolated from the steady-state community, whereas when a constant temperature of $8{ }^{\circ} \mathrm{C}$ was used the strain CR3/F/w/2/10 became the dominant organism (Upton et al., 1990).

Strain $1 / 15$ is a Gram-negative, motile short rod; and strain $2 / 10$ is a Gram-negative, motile coccoid rod. Both strains are capable of growth at $0{ }^{\circ} \mathrm{C}$; however, the optimum and maximum growth temperatures of strain $1 / 15$ are 9.7 and $26.5^{\circ} \mathrm{C}$, whereas those of strain $2 / 10$ are 20.9 and $32.0{ }^{\circ} \mathrm{C}$ (Upton, 1988).

Growth of cultures. Bacteria were grown in a nutrient-rich medium and in a nutrient-poor medium. The rich medium was a modified casein-peptone starch (CPS) medium based on the CPSA medium of Wynn-Williams (1979) containing casein, peptone, glycerol and glucose (as substitute for soluble starch) as carbon/energy sources, and the poor medium was a modified FC2 medium based on the FC2 medium of Brown \& Stanley (1972) containing glycerol as the carbon/ energy source; the media are described by Upton (1988). Batch cultures were grown at 5 or $20^{\circ} \mathrm{C}$ in a temperature-controlled gyratory incubator, and the bacteria harvested from mid-exponential phase cultures by centrifugation at $8000 \mathrm{~g}\left(r_{\mathrm{av} .}=6.98 \mathrm{~cm}\right)$ for $10 \mathrm{~min}$.

Lipid extraction. Total lipid was extracted from bacterial cell pellets using the method of Bligh \& Dyer as described in Kates (1986), and the fatty acid methyl esters prepared by transmethylation using $2.5 \%(\mathrm{v} / \mathrm{v})$ $\mathrm{H}_{2} \mathrm{SO}_{4}$ in dry methanol and analysed by GLC as described previously (Russell \& Volkman, 1980).

Transport assays. For transport assays, bacteria were harvested by centrifugation from mid-exponential-phase cultures (vide supra), washed twice with $50 \mathrm{~mm}$-sodium/potassium phosphate buffer, $\mathrm{pH} 6.8$, and resuspended in $6.0 \mathrm{ml}$ of the same buffer at a density equivalent to $\mathrm{OD}_{500}=0 \cdot 10\left(\right.$ approx. $\left.30 \mu \mathrm{g} \mathrm{dry} \mathrm{wt} \mathrm{ml}^{-1}\right)$. The assay was started by the addition of $1.2 \mu \mathrm{Ci}(6 \mu \mathrm{l})$ of $\left[\mathrm{U}^{-14} \mathrm{C}\right]$ glucose (Amersham, $230 \mathrm{Ci} \mathrm{mol}^{-1}$; $\left.8.5 \mathrm{TBq} \mathrm{mol}^{-1}\right)$. Incubations were performed at 0 or $20^{\circ} \mathrm{C}$ in a reciprocal-shaking water bath. Samples $(0.8 \mathrm{ml})$ were withdrawn at intervals, filtered through Whatman GF/C filters and washed with the phosphate buffer. The filters were dried, and counted in Lumogel scintillation cocktail (May \& Baker) using an LKB Rack-beta liquid scintillation spectrometer equipped with an external standards ratio facility for determination of counting efficiency. Control experiments with killed bacteria or with no bacteria in the incubation mixture showed that there was no residual radioactivity adherent to the bacterial cells or the filters.

\section{Results}

\section{Fatty acid composition of strain $1 / 15$}

The major fatty acids in strain $1 / 15$ were branched-chain fatty acids, which comprised $93-98 \%$ of the total in cultures grown in nutrient-rich medium and $71-97 \%$ in nutrient-poor medium (Table 1). In both rich and poor media, and at all growth temperatures, the predominant

Table 1. Fatty acid composition of strain 1/15 grown at different temperatures in rich and poor medium

$\mathrm{CL}$, acyl chain length; br-FA, branched-chain fatty acid; tr, trace (i.e. $<0.5 \%$ ).

\begin{tabular}{|c|c|c|c|c|c|c|}
\hline \multirow{3}{*}{$\begin{array}{l}\text { Growth medium } \\
\text { Growth temp. }\left({ }^{\circ} \mathrm{C}\right) \ldots\end{array}$} & \multicolumn{6}{|c|}{ Fatty acid composition (wt $\%$ ) } \\
\hline & \multicolumn{3}{|c|}{ Rich } & \multicolumn{3}{|c|}{ Poor } \\
\hline & 5 & 10 & 20 & 5 & 10 & 20 \\
\hline \multicolumn{7}{|l|}{ Fatty acid } \\
\hline $12: 0$ & - & - & - & $1 \cdot 7$ & $2 \cdot 4$ & $3 \cdot 1$ \\
\hline $14: 0$ & - & - & - & $\operatorname{tr}$ & 1.4 & 0.9 \\
\hline Iso $14: 0$ & 0.8 & $\operatorname{tr}$ & $\operatorname{tr}$ & $\operatorname{tr}$ & $1 \cdot 2$ & $1 \cdot 3$ \\
\hline $15: 0$ & $6 \cdot 4$ & $4 \cdot 7$ & - & - & - & - \\
\hline Anteiso 15:0 & $90 \cdot 3$ & $85 \cdot 8$ & $78 \cdot 6$ & $83 \cdot 8$ & $62 \cdot 6$ & $61 \cdot 7$ \\
\hline $16: 0$ & $\operatorname{tr}$ & $1 \cdot 3$ & 2.0 & 1.6 & $13 \cdot 2$ & $17 \cdot 3$ \\
\hline $16: 1$ & - & - & - & - & 1.9 & 1.9 \\
\hline Iso $16: 0$ & $\operatorname{tr}$ & 1.5 & 4.9 & 0.6 & $4 \cdot 0$ & $6 \cdot 5$ \\
\hline Anteiso 17:0 & 1.9 & $6 \cdot 3$ & 14.4 & $12 \cdot 5$ & $7 \cdot 2$ & $1 \cdot 1$ \\
\hline $18: 0$ & - & - & - & - & $2 \cdot 7$ & $1 \cdot 1$ \\
\hline $18: 1$ & - & - & - & - & $2 \cdot 1$ & $1 \cdot 3$ \\
\hline Mean CL & 14.94 & $15 \cdot 10$ & $15 \cdot 34$ & $15 \cdot 21$ & $15 \cdot 18$ & $15 \cdot 10$ \\
\hline$\%$ br-FA & $93 \cdot 0$ & $93 \cdot 6$ & 97.9 & $96 \cdot 9$ & $75 \cdot 0$ & $70 \cdot 6$ \\
\hline
\end{tabular}


fatty acid was anteiso-branched 15:0. However, in poor medium a much greater variety of fatty acids was present, with up to $26 \% \mathrm{C}_{12}-\mathrm{C}_{18}$ straight-chain, saturated and unsaturated fatty acids.

In rich medium the main effect of a fall in growth temperature was a decrease in the proportion of anteiso $17: 0$ and a rise in that of anteiso $15: 0$; there was also an increase in straight-chain $15: 0$. Together these changes gave a decrease in the average fatty acid chain length and an increase in the ratio of anteiso to iso-branched fatty acids (Table 1).

In poor medium, the main effect of a fall in temperature was an increase in anteiso-branched-chain fatty acids and a decrease in iso-branched and straightchain fatty acids; in particular, there was a large decrease in the proportion of 16:0 (Table 1).

\section{Fatty acid composition of strain 2/10}

The major fatty acids in strain $2 / 10$ were straight-chain, even-numbered, mainly $16: 0$ and $16: 1$; branched-chain fatty acids were absent (Table 2).

Table 2. Fatty acid composition of strain 2/10 grown at different temperatures in rich and poor medium

UFA, unsaturated fatty acid; Cyc, cyclopropane fatty acid; CL, acyl chain length; tr, trace (i.e. $<0.5 \%$ ).

\begin{tabular}{|c|c|c|c|c|c|c|}
\hline \multirow{3}{*}{$\begin{array}{l}\text { Growth medium } \\
\text { Growth temp. }\left({ }^{\circ} \mathrm{C}\right)\end{array}$} & \multicolumn{6}{|c|}{ Fatty acid composition (wt $\%$ ) } \\
\hline & \multicolumn{3}{|c|}{ Rich } & \multicolumn{3}{|c|}{ Poor } \\
\hline & 5 & 10 & 20 & 5 & 10 & 20 \\
\hline \multicolumn{7}{|l|}{ Fatty acid } \\
\hline $12: 0$ & - & - & - & $1 \cdot 7$ & $1 \cdot 2$ & $0 \cdot 8$ \\
\hline $14: 0$ & - & $\operatorname{tr}$ & $\operatorname{tr}$ & $\operatorname{tr}$ & $\operatorname{tr}$ & $\operatorname{tr}$ \\
\hline $16: 0$ & $22 \cdot 2$ & $24 \cdot 3$ & $32 \cdot 0$ & $36 \cdot 7$ & $30 \cdot 8$ & $42 \cdot 3$ \\
\hline $16: 1$ & $74 \cdot 4$ & $70 \cdot 8$ & $59 \cdot 8$ & $54 \cdot 0$ & $49 \cdot 3$ & $23 \cdot 8$ \\
\hline Cyc 17:0 & - & $\operatorname{tr}$ & $4 \cdot 1$ & $4 \cdot 1$ & $11 \cdot 6$ & $25 \cdot 4$ \\
\hline $18: 0$ & - & - & - & $\operatorname{tr}$ & $\operatorname{tr}$ & $\operatorname{tr}$ \\
\hline $18: 1$ & $3 \cdot 1$ & $4 \cdot 0$ & $4 \cdot 1$ & $3 \cdot 1$ & $3 \cdot 4$ & $4 \cdot 4$ \\
\hline Others & - & - & - & - & $3 \cdot 6$ & $2 \cdot 6$ \\
\hline$\%$ UFA & $77 \cdot 5$ & $74 \cdot 8$ & $63 \cdot 9$ & $57 \cdot 1$ & $52 \cdot 7$ & $28 \cdot 2$ \\
\hline$\%(\mathrm{UFA}+\mathrm{Cyc})$ & $77 \cdot 5$ & $74 \cdot 8$ & $68 \cdot 0$ & $61 \cdot 2$ & $64 \cdot 3$ & $53 \cdot 6$ \\
\hline Mean CL & $16 \cdot 02$ & $15 \cdot 94$ & $16 \cdot 13$ & $15 \cdot 97$ & $16 \cdot 12$ & $16 \cdot 20$ \\
\hline
\end{tabular}

In both rich and poor media the main effect of a fall in temperature was an increase in the amount of unsaturated fatty acid which was only partly offset by a decrease in cyclopropane fatty acid (Table 2). The conversion of $16: 1$ to cyc 17:0 was more pronounced in the poor medium. There was no consistent temperaturedependent change in fatty acid chain length in the rich medium, but there was a relative shortening at lower temperatures in the poor medium (Table 2).

\section{Transport assays}

The initial rate of glucose uptake by both strains was faster at an assay temperature of $20^{\circ} \mathrm{C}$ compared with $0{ }^{\circ} \mathrm{C}$ irrespective of the growth medium composition and culture temperature used (Table 3). However, a comparison of the two strains shows that when they were grown in rich or poor medium at $20^{\circ} \mathrm{C}$ the rate of glucose uptake by strain $2 / 10$ was faster than that of strain $1 / 15$, whereas when they were grown at $5{ }^{\circ} \mathrm{C}$ in either medium the rate of uptake of glucose by strain $1 / 15$ was generally faster than that of strain $2 / 10$ (Table 3). The rate of glucose uptake by strain $1 / 15$ was particularly low when it was grown in either medium at $20^{\circ} \mathrm{C}$.

\section{Discussion}

The Antarctic bacteria used in this study have interesting fatty acid compositions in that, whilst the fatty acids of strain 2/10 are typical of other Gram-negative bacteria, those in strain $1 / 15$ are not, despite the fact that both isolates have been identified as Pseudomonas spp. Gram-negative bacteria generally contain evennumbered saturated and unsaturated fatty acids, whereas Gram-positive bacteria contain predominantly odd-numbered branched-chain fatty acids (Harwood \& Russell, 1984). Thus most Pseudomonas species contain $16: 0,16: 1$ and $18: 1$ as their major fatty acids (Wilkinson, 1988). However, some species of Pseudomonas have atypical fatty acid compositions, and Wilkinson (1988) lists four species containing significant

Table 3. Initial rates of uptake of glucose by strains $1 / 15$ and $2 / 10$

The glucose uptake rates are expressed as $10^{-4} \times$ d.p.m. $\min ^{-1}(\mathrm{mg} \text { bacterial dry weight })^{-1}$.

\begin{tabular}{|c|c|c|c|c|c|c|c|c|}
\hline \multirow{3}{*}{$\begin{array}{l}\text { Growth medium } \ldots \\
\text { Growth temp. }\left({ }^{\circ} \mathrm{C}\right) \ldots\end{array}$} & \multicolumn{4}{|c|}{ Strain $1 / 15$} & \multicolumn{4}{|c|}{ Strain $2 / 10$} \\
\hline & \multicolumn{2}{|c|}{ Rich } & \multicolumn{2}{|c|}{ Poor } & \multicolumn{2}{|c|}{ Rich } & \multicolumn{2}{|c|}{ Poor } \\
\hline & 5 & 20 & 5 & 20 & 5 & 20 & 5 & 20 \\
\hline \multicolumn{9}{|l|}{ Assay temp. $\left({ }^{\circ} \mathrm{C}\right)$} \\
\hline 0 & $201 \cdot 8$ & 81.8 & $279 \cdot 0$ & $17 \cdot 4$ & $200 \cdot 1$ & $338 \cdot 5$ & $131 \cdot 8$ & $149 \cdot 8$ \\
\hline 20 & $815 \cdot 4$ & $303 \cdot 0$ & 1574.9 & $242 \cdot 7$ & $693 \cdot 5$ & $1123 \cdot 1$ & $914 \cdot 0$ & $598 \cdot 8$ \\
\hline
\end{tabular}


amounts of branched-chain fatty acids; a single species, Pseudomonas perlurida, has anteiso-branched 15:0 as a major component - the same as found in the present study for strain $1 / 15$.

Another feature of the fatty acid composition of strain $1 / 15$ is that it depends on the type of growth medium used. There is a greater variety of fatty acid types in bacteria grown in poor medium, whose lipids contain fatty acids having shorter and longer chain lengths than the major anteiso-branched 15:0; moreover, they are of a different type - viz. even-numbered and straight-chain, rather than odd-numbered and branched. Their presence is not due to uptake from the culture medium, which does not contain lipid; in addition, the bacteria were washed free of residual spent culture fluid prior to lipid extraction. The data indicate that the primer specificity of fatty acid synthetase is probably regulated by the growth medium constituent(s) (Kaneda, 1977). There is also an indication that temperature change has the same effect, because in poor medium the variety of fatty acids is greater at higher temperatures. These observations would be relevant to the natural environment, where changes in nutrient availability could alter the lipid composition and hence the function of cellular membranes.

The thermal response of fatty acid composition of strain 1/15 also depends on the type of culture medium used. In rich medium the fatty acid chain length is altered but there is no change in the proportion of branched-chain fatty acids, whereas in poor medium both the pattern of fatty acid branching and the amount of branched-chain fatty acid relative to straight-chain saturated and unsaturated fatty acid is altered. In both media, the direction of the observed fatty acid change would give lower melting-point lipids in bacteria grown at the lower temperature, indicating that the lipid changes could be part of a mechanism to maintain membrane fluidity. The fact that medium composition has such a marked effect on fatty acid composition emphasizes how difficult it is to make direct comparisons between the results of different studies in which different growth media have been used. It also highlights the fact that the thermal modulation of membrane fatty acid composition in the environment may alter with nutrient supply. This could be relevant, for example, in the Antarctic fellfields during spring freeze-thaw cycles, when sugars and polyols are released from lichens and mosses, providing nutrients for a microbial bloom (Tearle, 1987).

The thermal response of fatty acid composition of strain $2 / 10$ is much less dependent on the growth medium composition. In both rich and poor media the predominant effect of a decrease in growth temperature is an increase in fatty acid unsaturation. However; there is a larger proportion of cyc 17:0 in bacteria grown in the poor medium compared to the rich medium. Cyclopropane fatty acids are made from the corresponding monounsaturated precursor, particularly at the end of growth in batch culture or when growth rate slows (Harwood \& Russell, 1984). In strain $2 / 10$ this effect is not due to differences in the phase of growth, since all batch cultures were harvested in mid-exponential phase. It is more likely to be an effect of growth rate, because the cultures grew more slowly in the poor medium.

It is clear from the present data that both psychrotrophic bacteria alter their fatty acid composition in response to changes in growth temperature. In a previous study by Herbert and co-workers of four psychrophilic Vibrio spp. and four psychrotrophic Pseudomonas spp. from Antarctica (reviewed by Herbert, 1980), it was found that the fatty acid and phospholipid compositions of the psychrophiles but not the psychrotrophs altered with changes in culture temperature. Furthermore, it was shown that the uptake/utilization of lactose and glucose by the psychrophiles was greatest at $0{ }^{\circ} \mathrm{C}$ and decreased up to $15-20^{\circ} \mathrm{C}$, whereas the psychrotrophs showed the converse, with a maximum at approximately $20^{\circ} \mathrm{C}$. EllisEvans \& Wynn-Williams (1985) showed that glucose uptake/utilization in a psychrotroph from a permanently-cold Antarctic environment was maximal at $0{ }^{\circ} \mathrm{C}$ but fell at higher temperatures, whereas the converse was true of a psychrotroph isolated from an environment that underwent regular thermal fluctuations. Thus it appears that psychrophiles, and possibly psychrotrophs from permanently-cold habitats, might be better adapted to growth at temperatures close to zero by virtue of their ability to modify their membrane-lipid fatty acid composition, and hence their ability to take up nutrients at low temperatures. However, there are reports of psychrotrophs, including Pseudomonas sp. (e.g. Wada et al., 1987), which alter their fatty acid composition in response to changes in temperature, but their ability to take up nutrients was not studied.

The present study provides data relevant to the hypothesis linking changes in fatty acid composition with the ability to take up nutrients efficiently and to grow at low temperatures, by comparing two psychrotrophs that have similar growth temperature ranges but dissimilar optimum growth temperatures. Both the strain having more 'psychrophilic' characteristics (1/15) and the strain with more 'psychrotrophic' characteristics $(2 / 10)$ modify their fatty acid compositions in response to changes in culture temperature. When they are grown at a low temperature $\left(5^{\circ} \mathrm{C}\right)$ the strain with more 'psychrophilic' characteristics $(1 / 15)$ takes up glucose better than does the strain with more 'psychrotrophic' characteristics $(2 / 10)$. When they are grown at a higher temperature $\left(20^{\circ} \mathrm{C}\right)$ the converse is true. Thus it appears that the 
psychrotroph which was isolated under a fluctuating thermal regime (strain 1/15) and has a more "psychrophilic' optimum growth temperature $\left(9.7^{\circ} \mathrm{C}\right)$ is better adapted to growth at low temperatures than the strain which was isolated under a constant thermal regime and has a more 'psychrotrophic' optimum growth temperature $\left(20.9^{\circ} \mathrm{C}\right)$. This observation agrees with the hypothesis discussed above, except that both strains modify their fatty acid composition - assuming that such changes do indeed have an effect on, for example, membrane fluidity, and therefore influence the activity of the glucose uptake system. Overall, the results of this study lend weight to the hypothesis that there is a relationship between the ability to modify membranelipid fatty acid composition and the thermal characteristics of an organism's habitat.

We are grateful to Drs D. B. Nedwell and A. C. Upton, University of Essex, U.K., for generously making available the two species of psychrotrophic bacteria. This work was carried out whilst N. F. was a Visiting Scientist in the Department of Biochemistry, University of Wales, Cardiff, supported by funds from the Ministry of Education, Science and Culture of Japan.

\section{References}

Baross, J. A. \& Morita, R. Y. (1978). Microbial life at low temperatures: ecological aspects. In Microbial Life in Extreme Environments, pp. 9-71. Edited by D. J. Kushner. London: Academic Press.

BhaKOO, M. \& Herbert, R. A. (1979). The effects of temperature on the fatty acid and phospholipid composition of four obligately psychrophilic Vibro spp. Archives of Microbiology 121, 121-127.

BhaKoo, M. \& Herbert, R. A. (1980). Fatty acid and phospholipid composition of five psychrotrophic Pseudomonas spp. grown at different temperatures. Archives of Microbiology 126, 51-55.

Brown, C. M. \& Stanley, S. O. (1972). Environment mediated changes in the cellular content of the 'pool' constituents and their associated changes in cell physiology. Journal of Applied Chemistry and Biotechnology 22, 363-389.

Delille, D. \& PERRET, E. (1989). Influence of temperature on the growth potential of southern polar marine bacteria. Microbial Ecology 18, 117-123.

Ellis-Evans, J. C. \& WynN-Williams, D. D. (1985). The interaction of soil and lake microflora at Signy Island. In Antarctic Nutrient Cycles and Food Webs, pp. 662-668. Edited by W. R. Siegfried, P. R. Condy \& R. M. Laws. Berlin: Springer-Verlag.
HARWOOD, J. L. \& RuSSELL, N. J. (1984). Lipids in Plants and Microbes. London: George Allen \& Unwin.

HERBERT, R. A. (1980). A comparative stud of the physiology of psychrotrophic and psychrophilic bacteria. in Psychrotrophic Microorganisms in Spoilage and Pathogenicity, pp. 1-16. Edited by T. A Roberts. London: Academic Press.

HeRberT, R. A. \& BHAKOO, M. (1979). Microbial growth at low temperatures. In Cold Tolerant Microbes in Spoilage and the Environment, pp. 1-16. Edited by A. D. Russell \& R. Fuller. London: Academic Press.

KANEDA, T. (1977). Fatty acids of the genus Bacillus: an example of branched-chain preference. Bacteriological Reviews 41, 391-418.

KATES, M. (1986). Techniques of Lipidology, 2nd edn. Amsterdam: Elsevier.

MORITA, R. Y. (1975). Psychrophilic bacteria. Bacteriological Reviews 29, 144-167.

RUSSELL, N. J. (1984). Mechanisms of thermal adaptation in bacteria: blueprints for survival. Trends in Biochemical Sciences 9, 108-112.

Russell, N. J. (1989). Functions of lipids: Structural roles and membrane functions. In Microbial Lipids, vol. 2, pp. 279-365. Edited by C. Ratledge \& S. G. Wilkinson. London: Academic Press.

Russell, N. J. (1990). Cold adaptation of microorganisms. Philosophical Transactions of The Royal Society B326, 595-611.

Russell, N. J.\& Volkman, J. K. (1980). The effect of temperature on wax ester composition in the psychrophilic bacterium Micrococcus cryophilus ATCC 15174. Journal of General Microbiology 118, $131-141$.

TEARLE, P. V. (1987). Cryptogamic carbohydrate release and microbial response during spring freeze-thaw cycles in Antarctic fellfield fines. Soil Biology and Biochemistry 19, 381-390.

UPTON, A. C. (1988). Comparative physiological adaptation of selected Antarctic microbial communities to low temperature. $\mathrm{PhD}$ thesis, University of Essex, U.K.

UPTON, A. C. \& NEDWELL, D. B. (1989). Temperature responses of bacteria isolated from different Antarctic environments. In University Research in Antarctica; Proceedings of British Antarctic Special Topic Award Scheme Symposium, November 1988. Edited by R. B. Heywood. Cambridge: British Antarctic Survey.

Upton, A. C., Nedweli, D. B. \& WynN-Williams, D. D. (1990). The selection of microbial communities by constant or fluctuating temperatures. FEMS Microbiology Ecology (in the Press).

Wada, M., Fukunaga, N. \& SaSaKI, S. (1987). Effect of growth temperature on phospholipid and fatty acid compositions in a psychrotrophic bacterium, Pseudomonas sp. strain E-3. Plant Cell Physiology 28, 1209-1217.

WILKINSON, S. G. (1988). Gram-negative bacteria. In Microbial Lipids, vol. 1, pp. 299-488. Edited by C. Ratledge \& S. G. Wilkinson. London: Academic Press.

WyNN-WILliams, D. D. (1979). Techniques used for studying terrestrial ecology in the maritime Antarctic. In Cold Tolerant Microbes in Spoilage and the Environment, pp. 67-82. Edited by A. D. Russell \& R. Fuller. London: Academic Press. 